\title{
Fascinaciones aplicadas: discursos artísticos de (re)colección
}

\section{Applied fascinations: artistic discourses of (re) collection}

\author{
TIPO DE TRABAJO: Comunicación.
}

\author{
PALABRAS CLAVE
}

Arte contemporáneo, Coleccionismo, Recopilación, Resignificación, Crítica institucional.

\author{
KEY WORDS
}

Contemporary Art, Collecting, Compilation, Resignification, Institutional Criticism.

\section{RESUMEN}

Esta comunicación propone la investigación de un cruce entre campos del sistema artístico tan aparentemente alejados entre sí como interdependientes en su configuración histórica: si el artista y el coleccionista han sido tradicionalmente dos figuras casi antagónicas en sus correspondientes roles de productor y consumidor, uno como generador de discursos liminares y el otro como cosificador institucionalizante de éstos, hoy nos encontramos con toda una serie de poéticas que hacen condición de operación lingüística de la recopilación de objetos culturales de una misma clase. Así, este estudio se focaliza en dilucidar las relaciones que pueden establecerse entre los dos tipos de mirada que implican las figuras implicadas, la escrutadora de lo real en el caso del artista y la seguidora de compleción en el del coleccionista, para deducir esos modos de prácticas artísticas que las sintetizan como lectura recopiladora para resignificar materiales previos y, por tanto, constituir nuevos sentidos de acceso a la complejidad del mundo. Para ello, propongo un recorrido por diversos proyectos de otros tantos artistas que, mediante el agenciamiento de estas estrategias de colección, nos proporcionan un variado abanico de retóricas muy reveladoras de lo que entiendo como unas formas de economía política de la representación particularmente definitorias de las posibilidades críticas que hoy pueden articularse desde la producción artística. Me sirvo, pues, del análisis comparado de muy diferentes obras para establecer los intereses y modos de recolección que en ellas se emplean, de manera que pueda dilucidarse un nexo común que permita comprender esa mirada que, más allá de la mítica idea de creación romántica, y, sobre todo, mucho más acá, piensa haciendo mediante la recopilación, selección y resignificación relacional de lo ya dado, en un ejercicio político de las imágenes que opera en y ante algunas de las condiciones más determinantes de nuestra contemporaneidad.

\section{ABSTRACT}

This paper proposes the investigation of a cross between fields of the artistic system so apparently far apart as interdependent in their historical configuration. The artist and the collector have traditionally been two almost antagonistic figures in their corresponding roles of producer and consumer, one as a generator of liminal discourses and the other as an institutionalizing seer of these. But today we find a whole series of poetics that make linguistic operation condition of the collection of cultural objects of the same class. Thus, this study focuses on elucidating the relationships that can be established between the two types of view implied by the figures involved: the scrutinizing of the real in the case of the artist and the follower of completion in that of the collector, in order to deduce these modes of artistic practices that synthesize them as a reading compiler to resignify previous materials and, therefore, constitute new meanings of access to the complexity of the world. To do this, I propose a tour of various projects by as many artists who, through the agency of these collection strategies, provide us with a wide range of very revealing rhetorics of what I understand as particularly representative forms of political economy of representation. critical possibilities that today can be articulated from the artistic production. I use, then, the comparative analysis of very different works to establish the interests and modes of collection that are used in them, so that a common link can be elucidated to understand that look that, beyond the mythical idea of romantic creation, and, above all, much more here, thinks doing by means of the collection, selection and relational resignification of what has already been given, in a political exercise of the images that it operates in and before some of the most determining conditions of our contemporaneity. 


\section{INTRODUCCIÓN}

Atenderé a continuación algunas razones de producción y discursividad de tres proyectos que fundamentan su proceso en la configuración de campos de contranarrativas interdisciplinares, mediante modos de producción semántica que se estructuran a partir de, prácticas de recopilación, recombinación, colección y resignificación relacional de muy diferentes materiales previos. Para ello, parto del presupuesto de que el principal modo de acceso hoy al acontecer del mundo es internáutico (google, youtube, redes sociales, etc.), por lo que, según señala Hito Steyerl (2018), la velocidad y saturación de datos que nos lo representan se produce como un fenómeno quizás aún no suficientemente advertido: la acción de ver ha sido desplazada por la decodificación de datos y metadatos, la estadística y el reconocimiento de pautas y modelos de consumo. Pues bien, frente a ello es que reconozco se producen las prácticas de recolección que aquí traigo, ya que se articulan en función de unas lecturas de "lo real" que implican una clara actividad del sujeto en la recepción, selección y ordenación discursiva de objetos -cosas tangibles- del mundo, lo cual va mucho más allá de la mera admisión de postproducciones algorítmicas a modo de relato hegemónico de un infinito cosmos de consumibles, para ofrecer miradas que recuperan la complejidad interpretativa de los modos de recepción, pues sólo pueden producirse deconstruyendo lo dado como realidad. Y lo consiguen mediante algo tan tradicional como es el acto de coleccionar.

\section{METODOLOGÍA}

En este sentido, voy a presentar concretamente tres proyectos artísticos cruzando distintos métodos de análisis: los siguientes trabajos tanto serán examinados mediante la descripción de sus estructuras como a través de una interpretación de su sentido operacional, con objeto de establecer una secuencia de la que se deduzca una comparativa entre ellos. Pero antes comentar tales obras, me acercaré a ese tipo de mirada que implican, pues entiendo que sus particulares modos recolectores establecen una interesante conjunción entre el hacer lenguaje del artista y el hacer compleción del coleccionista, dos actitudes ante el hecho estético que, más allá de su tradicional antagonismo histórico, pueden mostrar reveladores puntos de contacto.

\section{DESARROLLO}

En el año 2000 la directora Agnès Varda estrenaba Los espigadores y la espigadora, un filme que el crítico de cine Jordi Batlle (2008) celebraba así:

[...] La mujer o el hombre que antaño se agachaba para recoger trigo se ha convertido, en la era del internauta globalizado, en un homeless urbanita que intenta separar el grano de la paja en un universo proclive a la confusión. Esa sería la primera lectura de esta cinta poliédrica y multitentacular que también habla, con timbre de voz perfectamente adiestrado para la poesía, del propio cine en tanto que material en proceso de reciclaje: en unos tiempos en que la respetabilidad del cine basura y la del cine de alta cultura pueden darse un apretón de manos, no está de más ver cómo la basura real y el desperdicio tienen una próspera función en nuestra sociedad. Los restos de comida de un mercado al atardecer son la metáfora de los restos de imágenes de un siglo de cine que aún pueden servirnos para alimentarnos, nutrirnos y hacernos más fuertes.

En este universo que habitamos, tan "proclive a la confusión", lecturas sagaces como la de Varda nos muestran, precisamente, "cómo la basura real y el desperdicio tienen una próspera función en nuestra sociedad", sobre todo si entendemos esa "basura real" como todo lo que nos llueva desde fuera de nuestra condición de hiperconexión, y si, más específicamente, nos referimos a artistas que hacen de la recolección su modus operandi para articular proyectos. Esta gran metáfora de Varda, que el crítico limita a la historia del cine, la entiendo aquí como un tropo del tipo de pensamiento que genera el artista, a medio camino entre la intuición y la razón en su lectura del mundo, aquélla que, diría Nelson Goodman, hace mundos. Porque de modos de leer sus detalles y, después, de reescribir sus relatos, estoy hablando: de lo mismo que reclamaba Walter Benjamin (2005, p. 223) cuando apuntaba que "hay que investigar cómo se elevan las cosas a alegoría en Las flores del mal", por ejemplo. Indagar cómo cualquier cosa puede ser potencia de sentido si -y de ahí la alusión a unos poemas tan liminares como los de esa obra de Baudelaire- es reconocida en sus cualidades transgresoras respecto a su propia ortodoxia cultural.

En los particulares campos de recolección que vamos a visitar, el que recopila, escoge, y tal decisión de discriminación de ciertos elementos de lo real se funda en una capacidad de lectura que es sofisticada porque se da una clase particular de objetos que reconocer. Ello implica una clara focalización de la mirada -siempre activa como proceso continuo de búsqueda-, que vendrá determinada por su atención a todo aquello que se pueda relacionar con el campo de trabajo que define cada proceso proyectual: cada colección. Precisamente, en una de las entradas que dedica al coleccionismo en el Libro de los Pasajes, Benjamin (2005, p. 223) se refería a este acto de manera reveladora: 
Al coleccionar, lo decisivo es que el objeto sea liberado de todas sus funciones originales para entrar en la más íntima relación pensable con sus semejantes. Esta relación es diametralmente opuesta a la utilidad, y figura bajo la extraña categoría de la compleción. ¿Qué es esta 'compleción'? Es el grandioso intento de superar la completa irracionalidad de su mera presencia integrándolo en un nuevo sistema histórico creado particularmente: la colección.

Revelador, decía, y muy apropiado desde el enfoque que estoy planteando, este análisis del ensayista alemán, porque se expresa en términos artísticos, tanto de antiutilitarismo como de compleción, o lo que los artistas llamamos coherencia del proyecto. "La completa irracionalidad" de la "mera presencia" de cada objeto de recopilación, en nuestro caso como en la descripción benjaminiana, sólo adquiere sentido en su enmarcado mediante el resto de la colección: "La fascinación más profunda del coleccionista consiste en encerrar el objeto individual en un círculo mágico [...] Todo lo recordado, pensado y sabido se convierte en zócalo, marco, pedestal” (Benjamin 2005, p. 223). Si bien aquí un seguidor suyo "de libro" fue Marcel Broodthaers con su ya mítico Musée d'Art Moderne, Département des Aigles (1968-72) (David, 1992), innumerables autores han practicado todo tipo de modos de recopilación de los más diversos materiales para su resignificación como discurso artístico. Mas son tres, como decía, los que aquí me interesa relacionar.

Observemos, para empezar, cómo Rogelio López Cuenca trabaja un modo recolector que, si bien es formalmente análogo al del Département des Aigles de Broodthaers, adquiere sentidos bien diferentes, pues las colecciones del malagueño no actúan sólo sobre el sistema del arte, sino mediante la deconstrucción de los relatos hegemónicos de poder en distintos planos de sus manifestaciones, desde la producción de ciudades-marca a la negación de la historia socio-política de diferentes lugares. Como es bien sabido, el método de investigación que seguía el historiador Aby Warburg a principios del siglo XX era la organización de numerosos paneles (Warburg, 2010), cuyos temas - "colecciones" que serían las que le permitirían pensar y escribir como lo hacía- los deducía de las analogías iconológicas entre obras de toda la Historia del arte con los que los componía y reconfiguraba, rompiendo así la clásica temporalización lineal que, aún hoy, sigue caracterizando al mainstream de la disciplina. En 2010, Georges Didi-Huberman, comisariaba la exposición ATLAS ¿Cómo llevar el mundo a cuestas? en el Reina Sofía, y explicaba el sentido táctico de este tan artístico método warburguiano: “[...] El Atlas es una presentación sinóptica de diferencias, [...] un trabajo de montaje en el que se unen tiempos muy distintos. Es un shock. [...] Cualquier imagen interesante es una confrontación, una coexistencia de tiempos distintos" (Didi-Huberman, 2018).

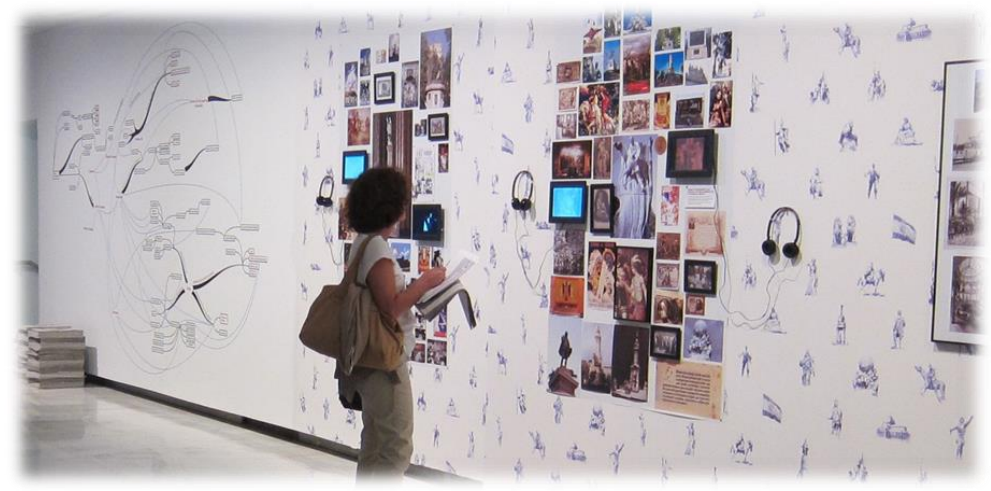

Figura 1. Taller Tras las huellas de la ciudad inconsciente. Rogelio López Cuenca \& Elo Vega (coords.) Los bárbaros. Lugares de memoria del colonialismo español en Madrid. Sala Alcalá 31, Madrid, 2016.

Pues bien, veamos cómo funciona este método en un proyecto que es resultado del trabajo colectivo que organizaron López Cuenca y Elo Vega en Madrid: el taller Tras las huellas de la ciudad insconsciente. Sus resultados se mostraron como parte de la exposición Los bárbaros (2016), que tuvo lugar en la sala Alcalá 31 de la ciudad, en una sección de la misma titulada Los bárbaros. Lugares de memoria del colonialismo español en Madrid (López Cuenca y Vega, 2016). En efecto, la recopilación de materiales que desmontaban el mito imperial que hoy nos siguen enunciando tantas erecciones conmemorativas en la capital del país, operaba mediante la acumulación de objetos en modo de reproducciones de esculturas, pinturas, grabados y fotografías, vídeos, anuncios publicitarios, etc., en cada uno, precisamente, de los paneles temáticos dedicados a la órbita de relaciones simbólicas y semánticas de cada monumento. $Y$ esos retablos estaban estructurados como yuxtaposiciones de muchos relatos tal cual, sin tocar. Era el enmarcado ${ }^{1}$

\footnotetext{
${ }^{1}$ Mieke Bal, verdadera adalid del concepto de enmarcado tal como lo vengo usando, defiende específicamente su capacidad de acción cultural del siguiente modo: "[El enmarcado y el reenmarcado actúan] demostrando de lo que son capaces de hacer los agentes culturales actuales: performar reflexiones, y no sólo ofrecerlas. [...] De hecho, el enmarcado constituye una forma de performance. Actuar en una actividad de mise-en-scène que traspasa la división imaginaria entre lo privado y lo público, entre los campos individuales y colectivos de existencia y vida: ésta es una tarea que corresponde a instituciones culturales como los museos. También es la del arte y la de los artistas que lo producen”. (Bal, 2009).
} 
producido por las relaciones internas entre elementos adyacentes en cada panel los que evidenciaban la vigencia, en el pasado y en el presente, del relato histórico oficial: sus silencios, ocultaciones y tergiversaciones, y la permanencia de su operatividad en la actualidad. Por tanto, insisto en cómo la clave de este tipo de prácticas reside en esa mirada "de bisturi" que encuentra en la cotidianeidad lo susceptible de ser recopilado y agenciado, porque lo reconoce como acontecimiento desde el foco del campo de trabajo en el que se esté operando. Miguel Morey $(1988$, p. 41) explica muy bien el plano actitudinal que requiere este mecanismo:

[...] Existe el acontecimiento salvaje porque existen y vivimos entre rebaños de acontecimientos domésticos. [...] Lo inesperado acarrea consigo un salto de intensidad que nos pone siempre en juego más allá de cualquier acontecimiento doméstico -nos jugamos eso que somos continuamente ante lo inesperado.

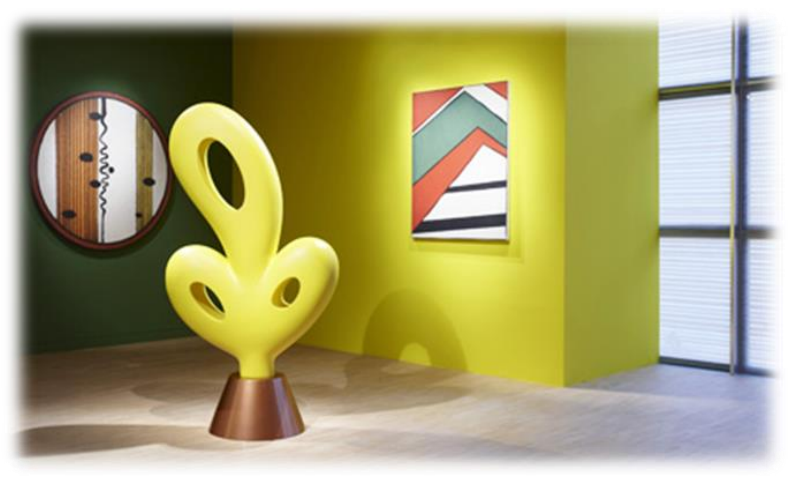

Figura 2. Bertrand Lavier. Walt Disney Productions 1947-2016. 2016

Nos la jugamos porque estamos en ello, y porque el juego es serio lo practicamos con fruición. De ahí proviene el hallazgo, el acontecimiento de encontrar otra pieza para el artilugio-colección. En este sentido, veamos otro proyecto, bien diferente, que surgió del encuentro casual (de nuevo, del acontecimiento), enmarcado, ahora, en un museo. Visitamos, pues, uno de arte moderno, acompañados de Minnie y Mickey Mouse en el no 1279 de Le Journal de Mickey (1977). Este paseo por las distintas salas del centro, titulado Traits très abstraits (Trazos demasiado abstractos), nos irá desgranando las distintas obras, efectivamente abstractas, que allí se exhiben, ante la mirada ciertamente extrañada de un Mickey que no acaba de comprender qué sentido tiene todo aquello. Otro espectador nos ha seguido en la visita. Es el artista francés Bertrand Lavier, quien no sólo está bien atento a los comentarios del ratón, sino que, como buen artista, escruta las obras en su lenguaje visual. Y ahí está su gran encuentro: reconoce las claves del código que han utilizado los dibujantes para representar las piezas allí expuestas, uno que se remite al imaginario universal de lo abstracto, por supuesto totalmente reducido a una serie de estilemas y tópicos gráficos para ello: verdaderas caricaturas del formalismo. Fascinado por la cuestión, Lavier va a coleccionar esas obras caricaturizadas que se ven en las diferentes viñetas de la historieta, para traerlas a su producción presencial como cuadros y esculturas a escala humana real (Lavier, 2012). Son, por tanto, réplicas de esa colección dibujada por Walt Disney Productions. Y con ellas está generando bucles de sentido: entre lo real y lo ficticio, entre la presencia objetual y la narración gráfica, entre los tópicos sobre la abstracción y los evidentes referentes concretos de las piezas dibujadas (Jean Arp o Kandinsky, por ejemplo). Esta semántica que hace del simulacro campo de trabajo, mantiene, sin embargo, y en ello reside el eje operativo de su agenciamiento resignificativo, un tipo de enfoque que ya estaba en la historieta: el tono netamente humorístico, que nos permite jugar a problematizar nuestros valores de recepción y aceptación del arte moderno y, más concretamente, los de su difusión cultural como relato banalizado.

Los bárbaros y Walt Disney Productions nos revelan cómo el plano particularmente interesante y significativo de sus intereses recolectores es su estrategia de movimiento de la focalización de la recepción estética, que funciona mediante un fuerte desplazamiento: desde la obra como objeto de contemplación a las operaciones de reenmarcado como discursos artísticos, de forma que el valor ya no reside tanto en las piezas concretas cuanto en el proceso de su resignificación, cada uno ya en función de los campos concretos que los definen. Y el caso del proyecto Fabiola de Francis Alÿs es paradigmático en este sentido (Alÿs, 2009). Este autor lleva casi treinta años coleccionando retratos de una mujer de perfil con un velo rojo sobre la cabellera. Pero su elección no es inocente: se trata -de nuevo, recordemos a Bertrand Lavier- de réplicas, aquí del retrato que el pintor académico francés Jacques Henner hiciese de Santa Fabiola en 1885, obra que hoy día está desaparecida. Otra vez un original ausente, como vemos. El retrato de Henner es una idealización de la santa a partir de la novela que le dedicase el cardenal inglés Nicholas Wiseman en 1884, que tuvo un éxito fulgurante, fue traducido a diez idiomas (aún se sigue reeditando), y generó una extensa devoción a esta figura que se mantiene hoy día en muchos países. El texto estaba basado en su primera biografía, que había redactado San Jerónimo en el s. IV, y narra cómo Fabiola, una patricia romana de riqueza abundante, abandonó a su esposo maltratador para volver a casarse. Viuda de este "segundo" marido a los pocos años, se convierte al cristianismo y dedica el resto de su vida y toda su fortuna a obras de caridad. Santa Fabiola, pues, es patrona oficial del oficio de enfermería y de las mujeres maltratadas. El caso es que el retrato de marras se volvió un icono, 
pues su demanda ha hecho que se reproduzca, además de en las típicas estampas, en todo tipo de formatos y materiales, realizadas por devotos y aficionados. Es decir, no por artistas de postín sino por personas anónimas. Y ésas son las piezas que colecciona Francis Alÿs, buscándolas en mercadillos y tiendas de antigüedades por cualquier lugar al que viaje.

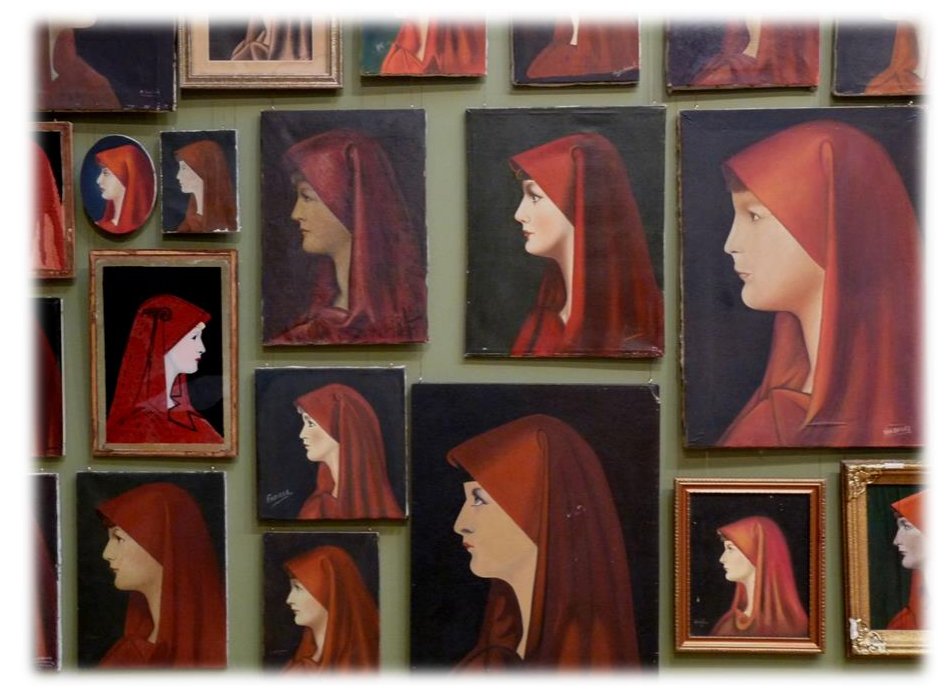

Figura 3. Francis Alÿs. Fabiola. 1990 - en curso

Es típico del trabajo de Francis Alÿs el empleo de la paradoja. El fino humor irónico que con el que genera sus proyectos se funda en ella por sistema. Y el de Fabiola es un caso paradigmático de proyecto articulado semánticamente como una sucesión de paradojas. Primero, el artista organiza las exposiciones de este proyecto como grandes acumulaciones de horror vacui, en las que la repetición del mismo motivo produce un shock al contrastar con la casi infinita variedad de sus registros, que nos hablan de una multiplicidad de procedencias -insisto, amateurs y anónimas- que resulta abrumadora. En segundo lugar, al exponer la colección en lugares habituales del gran arte, el conflicto receptivo es mayor. Ello orquesta, precisamente por la ausencia de pretensión discursiva de los retratos, un cosmos que sitúa el hecho de la producción de imágenes en un plano que resulta tan ajeno al contexto museográfico como cotidianamente habitual fuera de la institución arte: no son relatos hegemónicos, sino intrahistorias, lo cual cuestiona el propio concepto de hegemonía. En tercer lugar, la presencia masiva de esta "repetición de singularidades" excluye de forma radical el concepto de contemplación estética ante cada retrato, y nos lleva a reconocer que las funciones totalmente heteronómicas de su producción son mucho más comunes en el mundo que las de una pretendida autonomía de la obra de arte. Son imágenes de admiración o de devoción, no de contemplación.

\section{CONCLUSIONES}

Massimialiano Gioni, comisario de la exposición The Keeper (New Museum, NY, 2016), se preguntaba: “Ahora que nuestras más preciadas posesiones son completamente intangibles, inmateriales, e invisibles, ¿dónde podemos encontrar refugio? Si todo deviene data, ¿tendrán los objetos más, o menos peso?” (Gioni, 2016). Quizás estas líneas podrían servirle de (esperanzada) respuesta. De un modo $u$ otro, estos tres proyectos articulan una multiplicidad de voces anónimas en las que el concepto de autoría está muy disuelto en el de colectividad. Son tres lecturas de recopilación de cosas que las organizan en colecciones como contrarrelatos, unos muy particulares en los que, bergsonianamente, la percepción no es sino una función de tiempo (Bergson, 2016): estas colecciones, en efecto, generan temporalidades alternativas porque proporcionan otros puntos de vista respecto al mundo. Son, en fin, poéticas políticas que manifiestan diferentes planos de la crítica institucional, y que nos llevan a ámbitos y modos de entenderla que, como hemos visto, devienen directamente de la ubicación procesual -el coleccionismo-, de sus autores como productores, en unas prácticas muy significativas de todo un horizonte de representación característico de nuestro presente. 


\section{FUENTES REFERENCIALES}

Alÿs, F. (2009). Fabiola. Madrid: Museo Nacional Centro de Arte Reina Sofía.

Bal, M. (2009). Conceptos viajeros en las humanidades. Una guía de viaje. Murcia: Cendeac.

Batlle Caminal, J. (2008, mayo 29). Los espigadores y la espigadora. Fotogramas. Recuperado 4 de diciembre de 2018, https://www.fotogramas.es/peliculas-criticas/a8811/los-espigadores-y-la-espigadora/

Benjamin, W. (2005). Libro de los Pasajes. Madrid: Akal.

Bergson, H. (2016). Materia y memoria. Madrid: Cactus.

David, C. (Comisaria). (1992): Marcel Broodthaers. Madrid: Museo Nacional Centro de Arte Reina Sofía.

Entrevista con Georges Didi-Huberman acerca de la exposición ATLAS ¿Cómo llevar el mundo a cuestas? en el MNCARS. Recuperado de https://youtu.be/WwVMni3b2Zo

Gioni, M. (2016). The Country of Last Things. En Gioni, M. y Bell, N. (Eds.), The Keeper (pp. 10-15). Nueva York: New Museum.

Lavier, B. (2012). Walt Disney Productions. París: Éditions Dilecta.

López Cuenca, R. y Vega, E. (Coords.). (2016). Los bárbaros. Lugares de memoria del colonialismo español en Madrid. Madrid: Comunidad de Madrid. Recuperado de: https://www.lopezcuenca.com/los-barbaros/

Morey, M. (1988). El orden de los acontecimientos. Sobre el saber narrativo. Barcelona: Península.

Steyerl, H. (2018). Arte Duty Free. Madrid: Caja Negra Ed.

Varda, A. (Prod.), Varda, A. (Dir.). (2000). Les glaneurs et la glaneuse. Francia: Ciné Tamaris.

Warburg, A. (2010). Atlas Mnemosyne. Madrid: Akal. 